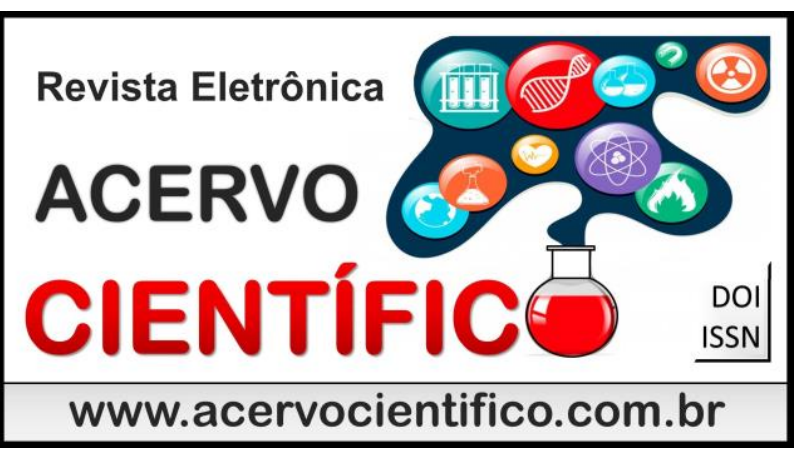

DOI: 10.25248/REAC.e332.2019

Recebido em: 8/2018

Aceito em: $8 / 2018$

Publicado em: 9/2018

\title{
Abertura política e econômica para a inserção do protestantismo em Angola
}

\author{
Political and economic opening for the insertion of Protestantism in Angola
}

Apertura política y económica para la inserción del protestantismo en Angola

\section{Antónia João Mussaque ${ }^{1}$}

\begin{abstract}
Resumo: Este artigo tem por objetivos descrever os mecanismos pelos quais o cristianismo se inseriu em Angola, primeiro representado pelo catolicismo atrelado a colonização portuguesa e a posterior pelo protestantismo, cuja inserção foi facilitada pela abertura politica e econômica da conferência de Berlim de 1884 a 1885 que, por intermédios de missões e missionários europeus e americanos, tornam-se coparticipantes pelo viés religioso, do movimento expansionista colonial europeu no Continente africano. Pretende também analisar o impacto causado pela imposição cultural e religiosa europeia aos valores linguísticos, culturais e religiosos nativos determinantes para a manutenção, preservação e continuidade, baseados na tradição ancestral africana, cujos efeitos ainda são visíveis nos dias atuais. Esta será uma pesquisa bibliográfica com descrição antropológica e histórica dos fatos recolhidos.
\end{abstract}

Palavras-chave: Angola, línguas, Culturas, Religião, Cristianismo.

\begin{abstract}
This article aims to describe the mechanisms by which Christianity was inserted in Angola, first represented by Catholicism linked to Portuguese colonization and later by Protestantism, whose insertion was facilitated by the political and economic opening of the Berlin conference from 1884 to 1885 , through European and American missions and missionaries, become co-participants through the religious bias of the European colonial expansionist movement in the African continent. It also intends to analyze the impact of European cultural and religious imposition on the native linguistic, cultural and religious values that are crucial to the maintenance, preservation and continuity, based on the African ancestral tradition, whose effects are still visible today. This will be a bibliographical research with an anthropological and historical description of the facts collected.
\end{abstract}

Keywords: Angola, languages, Cultures, Religion, Christianity.

Resumen: Este artículo tiene como objetivo describir los mecanismos por los que el cristianismo se insertó en Angola, primero representado por la colonización portuguesa catolicismo ligado y más tarde por el protestantismo, cuya integración fue facilitado por la apertura política y económica de la Conferencia de Berlín 1884-1885 que, por medio de misiones y misioneros europeos y estadounidenses, se vuelven coparticipantes por el sesgo religioso, del movimiento expansionista colonial europeo en el continente africano. También pretende analizar el impacto causado por la imposición cultural y religiosa europea a los valores lingüísticos, culturales y religiosos nativos determinantes para el mantenimiento, la preservación y la continuidad, basados en la tradición ancestral africana, cuyos efectos todavía son visibles en los días actuales. Esta será una investigación bibliográfica con descripción antropológica e histórica de los hechos recogidos.

Palabras clave: Angola, lenguas, culturas, Religión, Cristianismo.

1 Bacharel em Teologia e Especialista em Gestão e Docência do Ensino Superior pela Universidade Luterana do Brasil, Mestranda do curso de Ciências da Religião pela Universidade Presbiteriana Mackenzie, São Paulo-SP. * E-mail: nguevemalika@yahoo.com.br. 


\section{INTRODUÇÃO}

Angola é um país situado na região austral da África, a parte do continente que se localiza a sul do Saara. Fazem parte desta região os seguintes países: Angola, África do Sul, República Democrática do Congo, República do Congo, Lesoto, Malaui, Moçambique, Tanzânia, Namíbia, Suazilândia, Zâmbia e Zimbabwe. A população desses países tem hábitos e costumes diferentes, fala diferentes línguas nativas com algumas similaridades com caraterísticas própria dos povos Bantu ${ }^{2}$ e Khoisan ${ }^{3}$. Os países adotaram oficialmente a língua portuguesa como é o caso de Angola e Moçambique, o francês nos dois Congos e a língua inglesa nos restantes países.

O objetivo deste artigo é descrever o impacto produzido pela imposição cultural e religiosa europeia sobre a organização nativa, cuja inserção nada pacifica ocorreu na época colonial, processo facilitado pelo surgimento e desenvolvimento da técnica e da tecnologia pela Europa, gerando desta forma uma grande movimentação politica e econômica com uma vasta gama de interessados, dentre eles os religiosos.

O tema deste artigo surge assim em decorrência de pesquisas realizadas sobre vários temas ligados à educação, à cultura, religião e outros aspectos da vivência da população angolana desde a época précolonial até aos dias atuais, e da grande necessidade de documentar fatos sobre esta região africana que pode, pela sua grande diversidade cultural, fazer parte de estudos acadêmicos pertinentes para todas as ciências.

Esta pesquisa levanta a hipótese de que, o protestantismo derivado da Reforma preconizada pelo monge Martinho Lutero e seus colaboradores no século XVI, tardou a chegar a Angola devido a questões políticas e econômicas e religiosas dos tradicionais colonizadores do território, mas ainda assim, conseguiu inserir-se em Angola no contexto colonial português com hegemonia católica, facilitado pelos acordos de partilha dos territórios elaborados pela Conferência de Berlim de 1884 a 1885, e assim como no caso português com o catolicismo, o protestantismo também foi parte integrante do sistema de expansão e ocupação proposta por colonizadores imperialistas europeus em África.

\section{Reinos autóctones de Angola}

$\mathrm{O}$ ano de 1482 marca o início dos contatos pessoais entre portugueses e africanos de Angola. Os portugueses aportaram pela primeira vez na foz do rio Zaire liderado pelo navegador Diogo Cão, firmando os primeiros relacionamentos por meio de acordos diplomáticos entre o reino do Congo e o reino de Portugal (NETO, 2014,p.50).

Antes da invasão colonial aos domínios angolanos, existiam espalhados pelo território vários reinos que agrupavam as mais diversas etnias e grupos linguísticos como se segue: o reino do Congo, reinos do Ndongo e Matamba, reino da Kissama, reinos do planalto, reino de Kassange, reinos da Lunda Tchokwe e reinos do Sudoeste. De norte a sul e no leste, havia reinos grandes e pequenos constituídos de povos Bantu e não Bantu, como é o caso dos Khoisan e os Vátuas, o ajuntamento de determinado povo ou famílias que têm em comum os símbolos culturais, hábitos, costumes e falam a mesma língua (NETO, 2014,p.40).

Quanto às religiões tradicionais africana, também conhecida por animista, embora desprovida de escritura e de princípios doutrinários e eclesiásticos a semelhança dos ocidentais, enfatiza a existência de um Deus supremo e de seres espirituais incluindo os espíritos ancestrais, estes que fazem parte, influenciam e estão presentes na vida da comunidade. São por isso venerados, respeitados e invocados para o bem estar social, econômico e politico ( HENDERSON, 2001,p.32-33).

\footnotetext{
2 Wilhelm Bleek, linguista alemão, propôs o termo banto em 1856 para se referir a uma "família" de línguas que usavam uma raiz ntu para "pessoa»: muntu, singular, e bantu, plural. HENDERSON LWA, Igreja em Angola, 2001, p.19.

${ }^{3}$ Os Khoisan conhecidos pela sua pequena estatura, cor amarelada e olhos com prega mongólica igual a dos orientais, são possivelmente os primeiros homens que habitaram a África Austral antes da chegada dos bantu. NETO TS, Historia da educação e cultura de Angola, 2014, p. 39.
} 


\subsection{Chegada portuguesa e o estabelecimento da colonização em Angola}

Os portugueses chegaram a Angola no ano de 1482, estabeleceram contatos com o rei Nzinga Nkuvu, o soberano do reino do Congo, dando assim início à presença colonial portuguesa nos domínios angolanos. Por isso mesmo, diz-se que os portugueses não descobriram esta terra, eles a encontraram. Aquando da chegada portuguesa à terra que hoje se chama Angola, habitavam espalhados pelo território vários povos calculados entre 90 a 100 grupos etnolinguistico, grupos pertencentes ao conjunto bantu oriundos da região central, austral e oriental de África (CHAVES, Mateus Justino. O papel reconciliador da igreja no pós-guerra civil em Angola, 2008, p.21).

Firmando os acordos diplomáticos e comerciais entre o reino do Congo e o reino de Portugal e não havendo impedimentos ou resistência, no seu regresso a Portugal, Diogo Cão, o protagonista do primeiro contato com povos de Angola, leva consigo para Portugal, emissários do Rei Nzinga Nkuvu a fim de constatar a veracidade da aliança estabelecida com o reino distante de Portugal. No regresso, os emissários relatam com entusiasmo e deslumbre sobre as riquezas daquele reino, a capacidade técnica, os edifícios, os armamentos a religião, o que reforça a decisão do rei em converter-se ao catolicismo, pesando os benefícios que Ihes podiam advir desta aliança. O rei Nzinga Nkuvu e sua esposa foram batizados e doravante passaram a chamar-se D. João I e sua esposa de D. Leonor, a semelhança dos reis europeus (CALDEIRA, Arlindo Manuel. Escravos e Traficantes no Império Portugues. 2013,p.80).

Com prestimosa ajuda dos sacerdotes católicos instalados $\mathrm{n}$ o reino do Congo por anuência do rei e da maioria de seus súbditos, os nomes de vários súbditos do reino também foram mudados e adequados à cultura europeia bem como a toponímia dos lugares do reino. A capital do reino chamada de Mbanza Congo passou a chamar-se São Salvador. O rei tornou-se um grande defensor do cristianismo em seu reino, tornando-se impiedoso e severo contra todos que teimavam em praticar a religião tradicional de seus antepassados. Na sequência, chegam ao reino do Congo por anuência do rei, padres, missionários e religiosos imbuídos da tarefa de converter pela pregação todos os pagãos do reino do Congo, dando a eles a oportunidade da salvação pelo batismo (NETO, 2014, p. 53).

Com esta abertura aos portugueses, o reino do Congo tornou-se o primeiro reino africano a aceitar os ideais do cristianismo de forma pacífica e voluntária, ao menos por parte da liderança política. Ao aceitar cristianizar-se, o rei também declarou o catolicismo e a fé católica obrigatória em seus domínios. O rei, pessoalmente, tornou-se um grande influenciador fomentando projetos de construção de templos, escolas para catequese para introduzir não só a religião como também a língua portuguesa na vida material, nos costumes e nas instituições políticas (NETO, 2014,p.52).

A aceitação dos reis e súbditos do Congo dos pressupostos europeus marca o início do longo processo de anulação da identidade e dos valores culturais nativos angolanos estabelecidos por gerações, modelos norteadores da continuidade e preservação dos povos. A livre e espontânea adoção do modelo de cultura e religião estrangeira veio com certeza de constituir-se o meio facilitador da colonização portuguesa em Angola com todos os seus horrores, como afirma Neto (2014):

A partir daí, a sociedade nativa se desintegrou, perdeu parte de sua identidade, a força e a vitalidade que existia na nação, se desestruturou. Em seguida, os colonizadores implantaram as guerras, dividiram as famílias, deram nomes ocidentais aos nativos, apoderaram-se das terras, tornaram escravos os nativos e pilharam as riquezas da terra(NETO, 2014,p.

\section{Função do catolicismo na ocupação e dominação de Angola}

Estabelecidos e acomodados no reino do Congo, gradualmente, os portugueses foram adentrando 0 interior do território a fim de conquistar outros reinos. O próximo reino a ser conquistado foi o reino do Ndongo, governado pelo rei Ngola Kiluanji, por isso os portugueses o chamaram o reino de Angola, de onde deriva o nome do país (CALDEIRA, 2013, p. 91).

A conquista de outros reinos foi gradualmente acontecendo mediante o enfraquecimento militar, econômico e moral dos reis e reinos que, ora subornados ou mesmo vencidos, não resistiram aos 
portugueses que, avantajados técnica e economicamente, tomaram de assalto suas possessões e suas gentes (CALDEIRA, 2013,p.96).

Com a conquista de todos os reinos, os portugueses criaram estratégias políticas e econômicas que transformaram Angola em um território anexo ao reino de Portugal, denominado colônia ou província ultramarina. Neste processo, a igreja católica sempre esteve presente, de braços dados com as ações imperialistas portuguesas no território. Ela mesma participou ativamente de várias ações repressivas junto das populações nativas, tendo mesmo em sua posse seus próprios escravos, mesmo não concordando com todas as práticas portuguesas contra os angolanos (NETO, 2014, p.62).

Para o desenvolvimento e a expansão do catolicismo a responsabilidade pela implantação da Igreja Católica em Angola foi assumida por duas entidades: o instituto do Padroado e a ação da Propaganda Fide. O Padroado inspirava-se no tratado entre a Igreja Católica e o Governo Português, o qual atribuía direito e responsabilidades especiais ao Estado pela expansão da fé nos territórios por ele controlados e a Propaganda Fide ou a Propagação da fé estava encarregada, aquando da sua fundação em 1622, da expansão da fé em todas as áreas de missão; ora, no século XVII Angola foi considerada uma área de missão (HENDERSON, 2001, p. 39).

A autoridade conferida a Portugal pela Propaganda Fide e pelo Padroado serviu de suporte para todas as manobras tanto comerciais, políticas e comerciais, quanto religiosas. Por este viés, missionários, ministros, religiosos e vocacionados católicos se instalavam e permaneciam nos territórios indicados para aí desenvolverem o trabalho missionário junto da população nativa, ao mesmo tempo em que prestavam serviço ao aparato governamental português instalado na colônia angolana (HENDERSON,2001,p. 39).

Deste modo, aceitar a entrada de missionários protestantes nas colônias portuguesas, como é o caso de angola e Moçambique, significava para Portugal aceitar representantes da coroa britânica e outros governos, o que implicaria uma partilha do território conquistado com altos custos. Assim, no processo de colonização, civilização e cristianização de Angola, o catolicismo serviu tanto para a evangelização e difusão através do oferecimento aos nativos angolanos dos "bens de salvação", quanto como ferramenta estratégica para invasão e reforço da classe dominadora (NETO, 2014,p.154,155).

\subsection{A Conferência de Bruxelas de 1870}

Até o final do século XVIII, a presença e soberania estrangeira na África, e a consequente exploração e dominação, era verificada somente em alguns territórios como é o caso de Angola e Moçambique que ficaram sob controle português; a Gambia ficou controlada pelos britânicos e o Senegal, pelos franceses (BRUNSCHWIG, Henri. A Partilha da África Negra.2015 p.13).

$\mathrm{Na}$ época desses acontecimentos, o que se conhecia da imensa África eram as áreas litorâneas adjacentes ao atlântico. Os territórios interioranos de África eram até então desconhecidas, devido em grande parte a dificuldades de acessar o interior por via fluvial, visto que na sua maioria, os rios apresentavam cursos de difícil trânsito. A apresentação do interior de África com sua grande diversidade cultural e geográfica foi feita por duas grandes figuras: Livingstone, o sábio, explorador, médico e missionário europeu que, juntamente com o desejo de anunciar o evangelho aos africanos, nutria também o interesse em descobrir a nascente do rio Nilo e o repórter Henry Morton Stanley, financiado pela New York Herald e o Daily Telegraph, o enviado às terras africanas para dar seguimento às pesquisas e descobertas de Livingstone após a sua morte (BRUNSCHWIG, 2015, p. 28-29).

No período de três anos, o destemido repórter Stanley, percorreu vários cursos de rios que o levaram a descobrir os caminhos que davam acesso às áreas interioranas da África a partir do leste do Congo, mais precisamente a região de Boma. "Ficavam assim conhecidos desde então, a África central, facilmente acessível pelo leste do continente". A descrição da riqueza humana e material desses territórios despertou e desencadeou uma frenética corrida a estas paragens que se mostravam bastantes promissoras para os imperialistas europeus, os quais ainda não detinham possessões na África, desencadeando deste modo uma frenética corrida para estas paragens que se mostravam bastante promissoras (BRUNSCHWIG, 2015, p. 28-29). 
Este é dos principais motivos da corrida frenética e disputa acirrada por implantação de monopólios e permanência nos territórios africanos durante o século XVIII e XIX, discussões que irão centrar-se nas demandas por exclusividade de exploração por parte dos tradicionais ocupantes do território, enquanto que os novos egressos irão defender a livre circulação e comércio entre os territórios e o direito à exploração. Em torno destes assuntos surgirão imediatos conflitos entre os interessados, divergências, que estão na base de dois grandes acontecimentos que deram corpo a crises e rupturas no continente negro: A Conferência de Bruxelas em 1870 e a Conferência de Berlim de 1884 a 1885 (NETO, 2014,p. 72).

A Conferência de Bruxelas foi convocada pelo rei Leopoldo II belga, e dela participaram exploradores e representantes das grandes sociedades geográficas de vários países que concordaram em fundar uma organização em prol de África para fins humanitários que se denominou Associação Internacional Africana, mas que não cumpriu os principio social estabelecido(BRUNSCHWIG, 2015,p. 30).

\subsection{A Conferência de Berlim de 1884 a 1855}

$\mathrm{Na}$ sequencia e para mediar à concorrência das nações imperialistas em toda a África, Otto Von Bismarck, o chanceler alemão, propôs e convocou a Conferência de Berlim em representação de todos os interessados, os países que já possuíam colônias em África e as que almejavam possuir. A Conferência foi aberta pelo príncipe Bismarck no dia 15 de novembro de 1884 "em nome de Deus, conforme começava o ato de Berlim". Participaram deste evento representantes dos seguintes países: Áustria-Hungria, Alemanha, Bélgica, Dinamarca, Estados Unidos, Espanha, França, Grã-Bretanha, Itália, Países Baixos, Portugal, o Imperador de todas as Rússias, representante da Suécia e da Noruega, e a representação do Império Otomano. No total, catorze países estiveram representados na Conferência (BRUNSCHWIG, 2015, p. 4142).

A Conferência de Berlim de 1884 a 1885 foi à reunião internacional responsável por concretizar as metas traçadas por colonialistas quanto aos parâmetros norteadores das ações comerciais e exploratórias impostas ao continente africano e como resultados as potências imperialistas europeias abocanharam vastos territórios para a instalação de seus monopólios, territórios que doravante tornaram-se províncias de seus respectivos países, dando-se o início a uma nova era, uma nova modalidade de colonização (NETO, 2014, p. 74)

A Conferência de Berlim de 1884 a1885 tratou especificamente de questões de interesses econômicos, políticos e religiosos, beneficiando deste modo a inserção de missionários em Angola especialmente o segmento protestante, este que em suas tentativas para adentrar em territórios já colonizados por Portugal encontrava sérias restrições. A presença de religiosos nas discussões referentes a políticas expansionistas e questões econômicas não é novidade no longo processo de descobertas e conquistas, visto que as missões de evangelização seguiam os caminhos abertos pelos exploradores e colonizadores (MUSSAQUI, 2016, p.36).

A ata geral redigida em Berlim no dia 26/02/1885, assinada por catorze representantes dos países presentes na Conferência, regulamentou a liberdade do comércio na bacia do Congo e do Níger, assim como novas ocupações de territórios sobre a costa ocidental da África. Esta ata preconiza também no seu primeiro capítulo, nos artigos primeiro, quinto e sexto, a liberdade comercial, a livre circulação entre os territórios, a liberdade religiosa acompanhada do livre e público exercício de todos os cultos, o direito de erigir edifícios religiosos e de organizar missões pertencentes a qualquer culto sem nenhuma restrição ou entrave (BRUNSCHWIG, 2015, p. 80-81).

Desse modo, a Conferência de Berlim de 1884 a 1885 possibilitou no que toca ao cristianismo protestante, a oportunidade de acessar todos os territórios sem exceção, incluindo as colônias portuguesas onde predominava o catolicismo. Estavam assim preparadas as condições para o protestantismo fazer parte do cenário religioso das colônias portuguesas, com particular destaque para o território angolano.

Em síntese, a Conferência de Berlim de 1884 a 1885 decretou o fim da exclusividade e supremacia do catolicismo em território africano, quase anulando os acordos de Portugal com Roma quanto a evangelização dos povos nativos dos territórios por estes colonizados (BRUNSCWIG, 2015,p. 82). 


\subsection{Protestantes em Angola}

Logo após a Conferência de Berlim de 1884 a 1885, após quase 400 anos de presença católica em Angola, começa a registrar-se a partilha religiosa, a presença efetiva de missionários protestantes provenientes da América e da Europa, com o é o caso da missão Batista, Metodista, a Missão dos Irmãos de Playmouth e outras que se instalam no território angolano no decorrer do séculoXVIII e XIX( HENDERSON, 2001,p.45, 69).

Assim como os portugueses católicos que os precederam no território, a presença missionária protestante do século XVIII e XIX significou para os povos africanos, em especial para as etnias de Angola, a continuidade da desestruturação, desvirtualização e imposição de pressupostos culturais europeus sobre os hábitos, costumes e formas religiosas de adoração africana, visto que estes também faziam parte do aparato colonial para o qual prestavam serviços por intermédio da religião. A participação e a conivência dos religiosos e missionários católicos e protestantes na ditadura colonial instalada nos mais diversos territórios africanos eram tão visíveis que, no decorrer do século XX e com o despertar de movimentos nacionalistas que se organizavam para lutar pela libertação do jugo colonial, ouvir-se-á por toda a África o brado: "settlers and missionaries, go to home" (colonizadores e missionários, voltem para a casa) (MUSSAQUI, 2016,p. 32).

Tal era indignação dos nativos ainda lúcidos contra todos os estrangeirismos e desserviço do cristianismo nas mais diversas nações africanas, que no decorrer do século XX surge no meio de igrejas protestante estabelecidas por missionários, dois grandes movimentos messiânicos, organizados contra a colonização religiosa: o Kimbaguismo (1921) com início na atual República Democrática do Congo e o Tocoísmo (1949) em Angola na vigência do sistema colonial português (NETO, 2014, p. 180 -183).

Estes dois movimentos surgem assim em decorrência da omissão dos missionários face ao sistema exploratório e desumano que se experimentava em quase toda a África, onde os missionários cristãos legitimavam a invasão de seus patrícios políticos colonizadores, dando provas da participação da igreja no movimento expansionista, colonizador e imperial dos países europeus, na tomada de assalto aos territórios africanos. Estes movimentos incentivaram os nativos angolanos a resistir ao colonizador por intermédio da perpetuação da cultura religiosa africana, segundo a tradição dos antepassados ( NETO, 2014,p. 184).

\section{CONSIDERAÇÕES FINAIS}

A história de Angola e em particular do movimento cristão está recheado de eventos marcantes de superação e heroísmo de seus habitantes. No nível da religião cristã, incluindo católicos e evangélicos, registra na sua trajetória vários eventos que possibilitaram a desestruturação dos sistemas autóctones préestabelecidos, não só no que tange a religião, como também da politica, economia e todos os sistemas de regência e organização social nativa.

Desse modo, fica constatada que, tanto o catolicismo que chegou a Angola de braços dados com o colonizador português, quanto o protestantismo, que se insere no território por intermédio da abertura politica e econômica possibilitada pela Conferência de Berlim de 1884 a 1885, agiram em consonância com o sistema colonial e de potências imperiais da Europa instaladas em África e em Angola com particular destaque, sendo desse modo parte do processo colonizador e explorador do Continente africano.

\section{REFERÊNCIAS}

1. BRUNSCHWIG, Henri. A partilha de África. São Paulo: Perspectiva, 2015.

2. CALDEIRA, Arlindo Manuel. Escravos e traficantes no império português. Lisboa: A Esfera do Livro, 2013.

3. CHAVES, Mateus Justino. O papel reconciliador da Igreja no pós-guerra civil em Angola. Anápolis: Transcultural, 2008.

4. HENDERSON, Lawrence W.A. Igreja em Angola. Luanda: Editorial Além-Mar, 2001.

5. NETO, Teresa da Silva. História da educação e cultura de Angola. Luanda: Zaina Editores, 2014.

6. MUSSAQUI, António Neves. O presbiterianismo em Angola: trinta anos de missão e serviço. São Paulo: Universidade Presbiteriana Mackenzie, 2016.

REAS, Revista Eletrônica Acervo Científico, 2018. Vol. 1, 24-29. 